\title{
Review Article \\ Herbal Medicine for the Treatment of Obesity: An Overview of Scientific Evidence from 2007 to 2017
}

\author{
Yanfei Liu, ${ }^{1,2}$ Mingyue Sun, ${ }^{2}$ Hezhi Yao, ${ }^{2}$ Yue Liu, ${ }^{3}$ and Rui Gao ${ }^{2}$ \\ ${ }^{1}$ Graduate School of Beijing University of Chinese Medicine, Beijing 100029, China \\ ${ }^{2}$ Institute of Clinical Pharmacology, Xiyuan Hospital of China Academy of Chinese Medical Sciences, Beijing 100091, China \\ ${ }^{3}$ Cardiovascular Diseases Center, Xiyuan Hospital of China Academy of Chinese Medical Sciences, Beijing 100091, China \\ Correspondence should be addressed to Yue Liu; liuyueheart@hotmail.com and Rui Gao; ruigao@126.com
}

Received 22 May 2017; Revised 21 July 2017; Accepted 15 August 2017; Published 25 September 2017

Academic Editor: Gorkem Kismali

Copyright (C) 2017 Yanfei Liu et al. This is an open access article distributed under the Creative Commons Attribution License, which permits unrestricted use, distribution, and reproduction in any medium, provided the original work is properly cited.

Obesity is a very common global health problem, and it is known to be linked to cardiovascular and cerebrovascular diseases. Western medical treatments for obesity have many drawbacks, including effects on monoamine neurotransmitters and the potential for drug abuse and dependency. The safety of these medications requires improvement. Herbal medicine has been used for treatment of disease for more than 2000 years, and it has proven efficacy. Many studies have confirmed that herbal medicine is effective in the treatment of obesity, but the mechanisms are not clear. This article will discuss the possible effects and mechanisms of herbal medicine treatments for obesity that have been reported in the past decade.

\section{Introduction}

Obesity is a metabolic disorder characterized by an excess accumulation of fat in the body due to energy intake exceeding energy expenditure [1]. Obesity is an increasingly common phenomenon all over the world. Body mass index (BMI) is the most commonly used measure to evaluate the degree of obesity. In 2016, the AACE (the American Association of Clinical Endocrinologists) released new diagnostic criteria of obesity based on BMI combined with obesity-related complications (see Table 1) [2]. The latest study, which analyzed data from 68.5 million persons between 1980 and 2015, found that a total of 107.7 million children and 603.7 million adults were obese in 2015 [3]. Obesity has become a worldwide epidemic, and the trend is becoming increasingly serious. Obesity is an independent risk factor for metabolic syndrome; major medical problems associated with the development of hypertension, type 2 diabetes (T2DM), dyslipidemia, sleep apnea, and respiratory disorders; and ultimately life-threatening cardiovascular disease (CVD), stroke, and certain types of cancer [4-6].

The number of obese patients is increasing globally [7]. Reducing body weight by lifestyle alteration is advisable, but sometimes drug intervention is necessary [8]. Obesity drugs can be divided into five categories: central appetite suppressants, digestion and absorption blockers, metabolic promoters, obesity gene product inhibitors, and other drugs for the treatment of obesity [9]. However, the weight loss drugs prescribed in conventional medicine induce many adverse reactions, primarily effecting monoamine neurotransmitters, and causing drug abuse or dependence [10]. For example, sibutramine has been reported to commonly cause adverse events, including dry mouth, insomnia, anorexia, constipation, formation of thrombi, and neurological symptoms [11, 12]. Surgery is commonly used in morbidly obese patients (BMI $\geq 40 \mathrm{~kg} / \mathrm{m}^{2}$ ) or in patients with comorbidities, such as hypertension, diabetes, and obstructive sleep apnea [13]. Common surgical complications include infection, postoperative anastomotic fistula, deep vein thrombosis, and long-term complications such as anemia and malnutrition $[14,15]$. Given the dangers of obesity and the shortcomings of western medicine, alternative treatments should be further investigated. This article examines the potential role of herbal medicines in the treatment of obesity and summarizes the scientific evidence reported from 2007 to 2017. 
TABLE 1: The new definition of obesity from the AACE* [2].

\begin{tabular}{lcc}
\hline Diagnosis & $\begin{array}{c}\text { Body mass } \\
\text { index (BMI) }\end{array}$ & $\begin{array}{c}\text { Clinical component } \\
\text { (complications) }\end{array}$ \\
\hline Overweight & $\geq 25-29.9$ & $\begin{array}{c}\text { No complications } \\
\text { Obesity stage 0 }\end{array}$ \\
Obesity stage 1 & $\geq 25$ & $\begin{array}{c}\text { No complications } \\
\text { One or more mild-to-moderate } \\
\text { complications }\end{array}$ \\
Obesity stage 2 & $\geq 25$ & $\begin{array}{c}\text { One or more severe } \\
\text { complications }\end{array}$ \\
\hline
\end{tabular}

*AACE: American Association of Clinical Endocrinologists.

\section{Methods}

The PubMed and Web of Science were searched for studies published from 2007 to 2017 on humans or animals. The search terms were "obesity," "obese," or "antiobesity" and "herbal medicine," "plant," "plant medicine," or "Chinese medicine" without narrowing or limiting search items. Relevant publications with available abstracts and titles were reviewed by two reviewers.

The Clinical Trials (https://clinicaltrials.gov/) and Chinese Clinical Trial Registry (http://www.chictr.org.cn/) databases were searched for registered clinical trials of herbal medicine and obesity. The search terms were "obesity" or "obese" and "herbal medicine," "plant," "plant medicine," or "Chinese medicine."

\section{Results}

3.1. The Role of Herbal Medicine in Treating Obesity: Evidence from Human Studies. Eighteen randomized controlled trials (RCTs) (sample size > 50 cases) [16-33] published from 2007 to 2017 were included. Studies of herbal medicine interventions for obesity that had no obvious effects were excluded. The contents of the included 18 published RCTs are shown in Table 2. Analysis of these studies found that the maximum number of subjects was only 182, and the sample size is small. The age of the subjects ranged from 18 to 79 years. The studies were performed in many different populations. Eleven studies [16-18, 20, 21, 23, 25, 28-30, 33] mentioned complications, including hypertension, impaired glucose tolerance, spleen hypofunction, excessive sweating, nonalcoholic fatty liver disease, hyperlipidemia, and metabolic syndrome. Of the 18 studies, 6 were completed by Chinese researchers, and the remaining 12 were from Japan, Australia, Canada, USA, Russia, France, Indonesia, Korea, Indian, Thailand, and Italy. Thus, herbal medicine interventions for obesity are being studied in more countries than China. The outcome of each study varied and could be roughly divided into the following categories: (1) change in body weight: a significant decrease in body weight occurred following treatment with xin-juxiao-gao-fang (XJXGF, compound of rhubarb, Coptis, semen cassiae, and Citrus aurantium), yellow pea fiber, bofu-tsushosan (compound of Radix Platycodi, Gypsum Fibrosum, talcum, Paeoniae, Scutellariae, and Glycyrrhizae), RCM-104 (compound of Camellia sinensis, flos sophorae, and semen

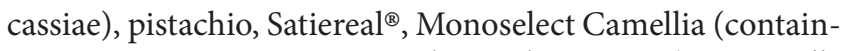
ing green tea extract: GreenSelect ${ }^{\circledR}$ Phytosome $^{\circledR}$ ), or Nigella sativa; (2) BMI: a significant decrease in body fat occurred following treatment with xin-ju-xiao-gao-fang, bofu-tsushosan, RCM-104, Linggui Zhugan Decoction (compound of poria, Macrocephalae, Radix Glycyrrhizae, Ramulus Cinnamomi, and Radix Atractylodis), Pu'er tea, pistachio, or Monoselect Camellia; (3) waist or hip circumference: there was a significant decrease in waist or hip circumferences treat with the following herbal medicine from six studies: xin-juxiao-gao-fang, Pu'er tea, Satiereal, Catechin enriched green tea, West African Plant (Irvingia gabonensis), and Cissus quadrangularis (Irvingia gabonensis); (4) food intake: two studies, of RCM-104 and yellow pea fiber, referred to the influence of traditional Chinese medicine on food intake, but data were not provided; (5) other effects: homeostatic model assessment-insulin resistance (HOMA-IR), homeostatic model assessment- $\beta$ cell function (HOMA- $\beta$ ), glycated hemoglobin (HbAlc), blood pressure (BP), quality of life, fasting insulin (FINS), and fasting plasma glucose (FPG) were detected in these trials; (6) evaluating these eighteen clinical studies based on Jadad score: it was found that the overall quality of these clinical studies is low. Of three studies, the Jadad score was 4 , and the remaining studies scored below 4 scores. We found 16 registered clinical trials (see Table 3 ) from https://clinicaltrials.gov/ and http://www.chictr.org.cn/, and the recruiting locations vary from China and Korea to United States and Portugal, which will provide greater scientific insight into the treatment of obesity by herbal medicine all over the world.

3.2. The Role of Herbal Medicine in Treating Obesity: Evidence from Animal Studies. In this section, we will summarize the known effects and mechanisms of action of single herbs and their components or extracts in animal models of obesity (see Table 4 and Figure 1).

3.2.1. Rhizoma Coptidis (Huang Lian). Rhizoma coptidis is derived from the root of Coptis chinensis Franch., Coptis deltoidea C. Y. Cheng et Hsiao, or Coptis teeta Wall [55]. Its main components include alkaloids and lignans. Among the alkaloids, berberine is a main active component of Rhizoma coptidis [34]. The studies found that Rhizoma coptidis can reduce weight, lower lipids [56], reduce lipid synthesis [57], and inhibit adipogenesis [58]. Xie et al. [35] found that Rhizoma coptidis (RC) $(200 \mathrm{mg} / \mathrm{kg})$ and berberine (200 mg/kg) significantly lowered body and visceral adipose weight, reduced blood glucose and lipid levels, and decreased degradation of dietary polysaccharides in high-fat diet (HFD) mice. Both the ex vivo and in vitro trials confirmed that RC and berberine can regulate gut microbes to reduce weight. The antiobesity mechanisms of RC and berberine involve decreasing degradation of dietary polysaccharides, lowering caloric intake, and systemically activating fasting-induced adipose factor (FIAF) protein and expression of genes related to mitochondrial energy metabolism. Zhang et al. [59] found that when $3 \mathrm{~T} 3-\mathrm{L} 1$ preadipocytes were cultured with various concentrations of berberine $(0,0.5,1,5$, or $10 \mu \mathrm{M})$ for 7 


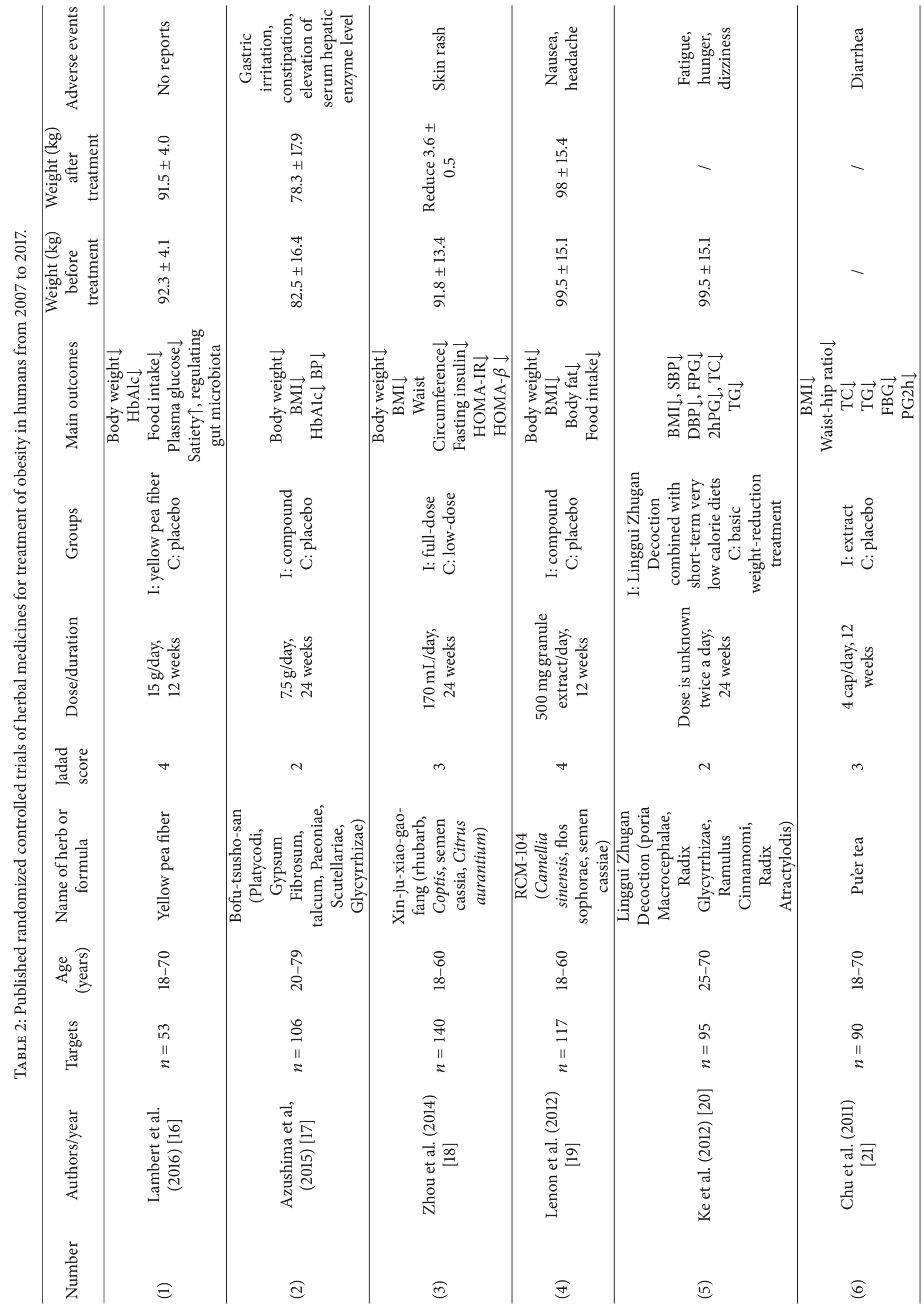




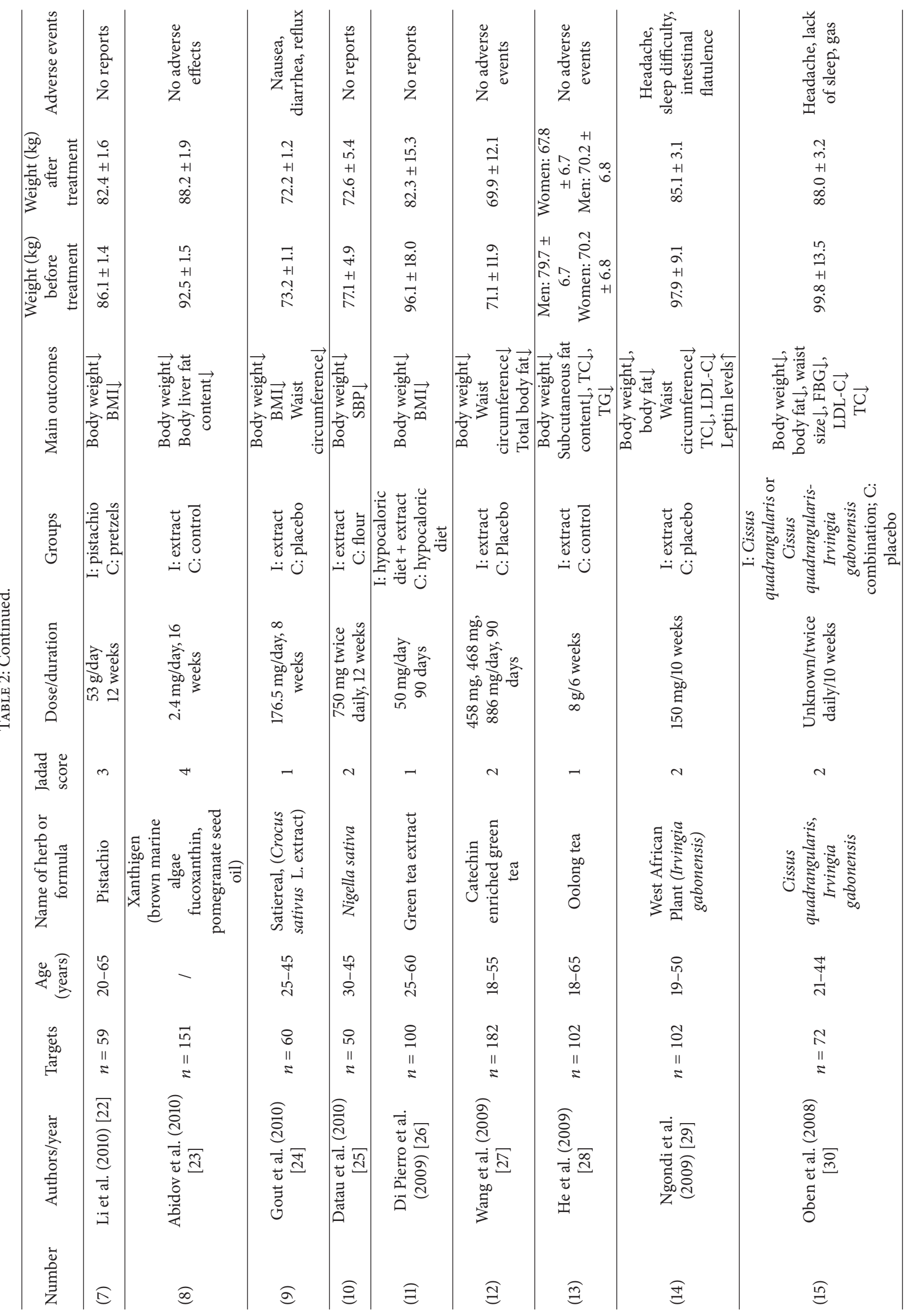




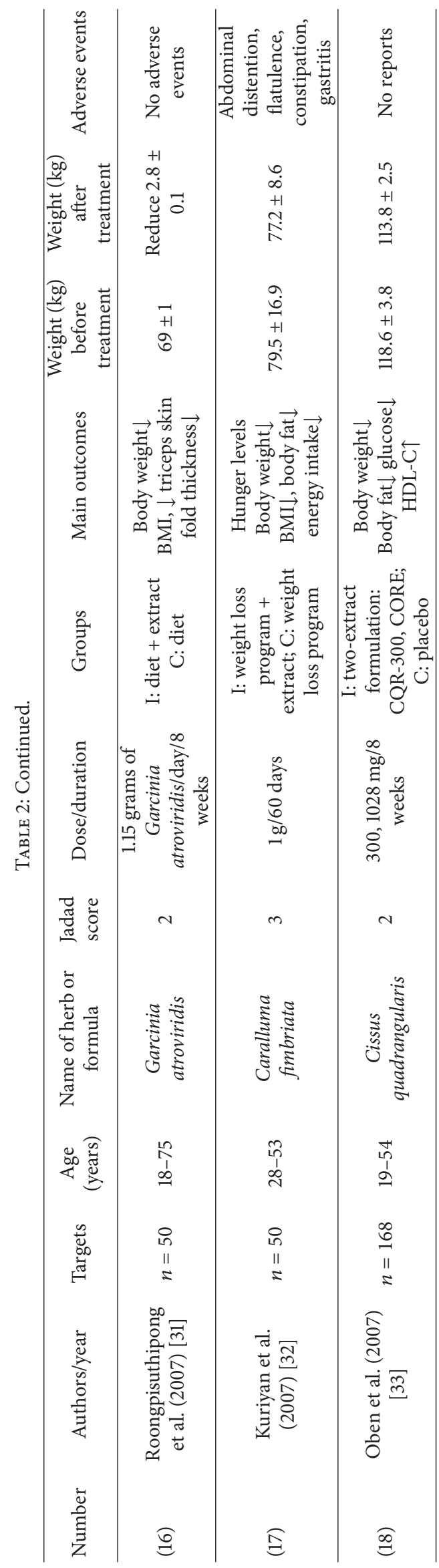




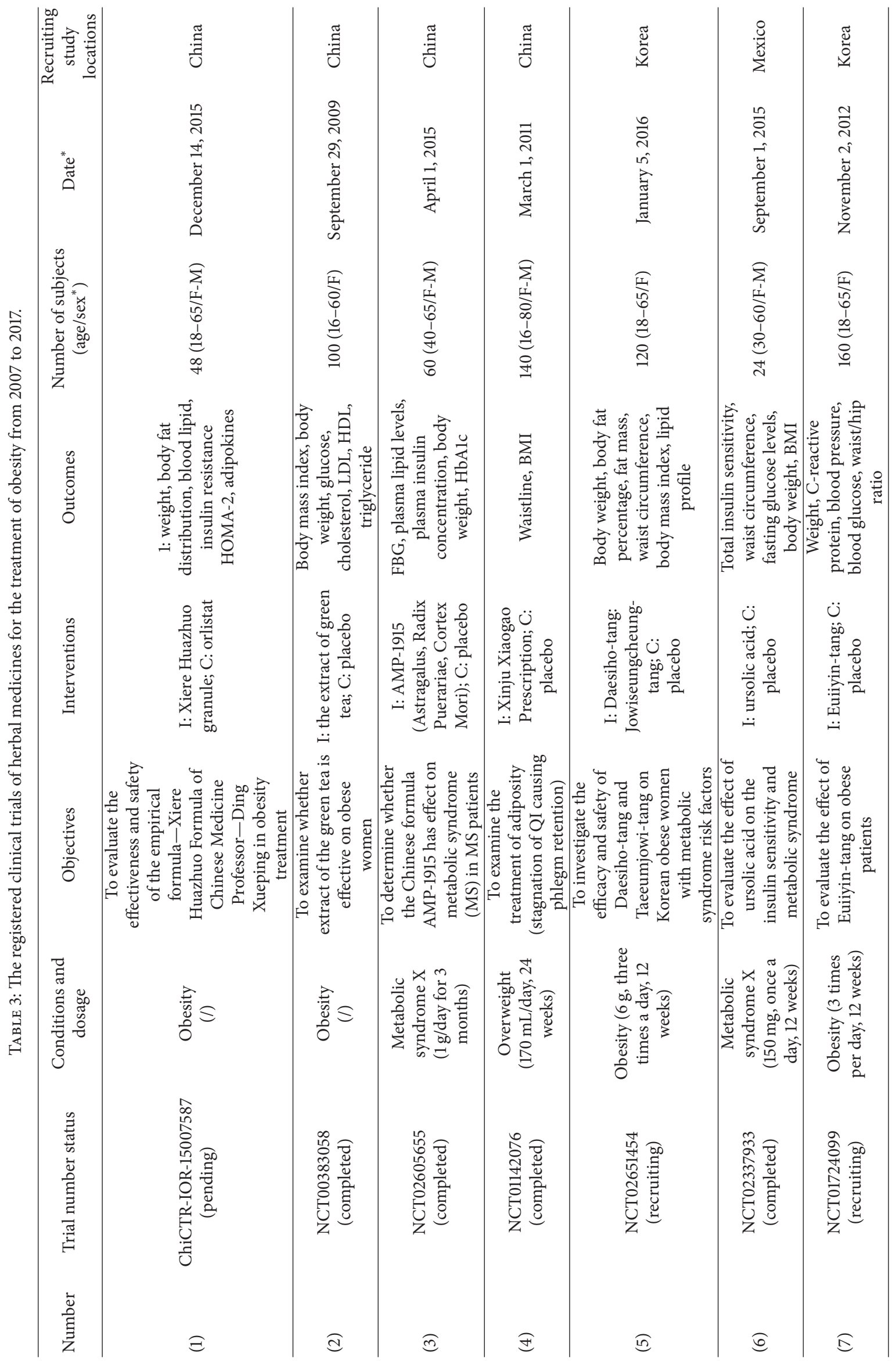




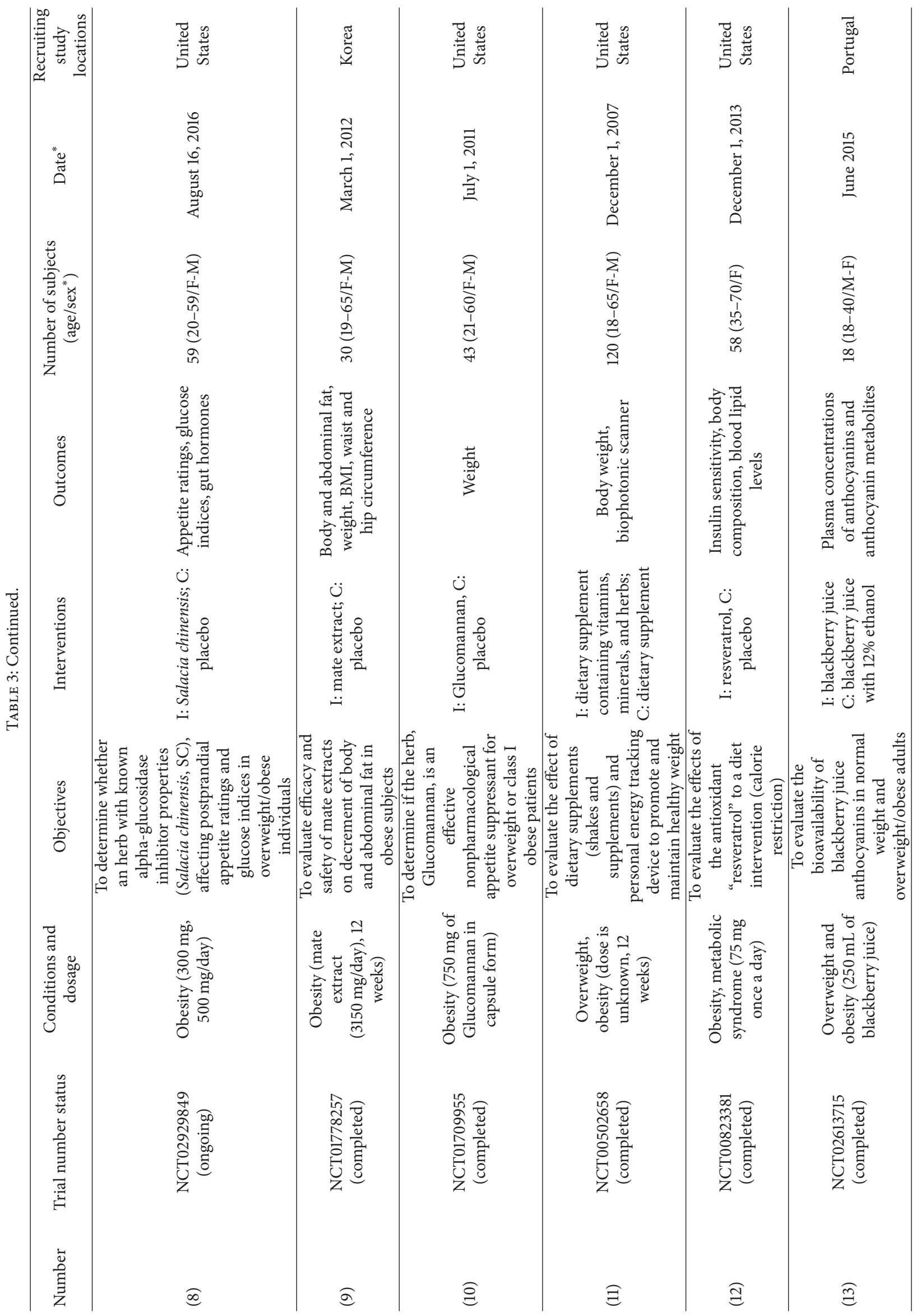




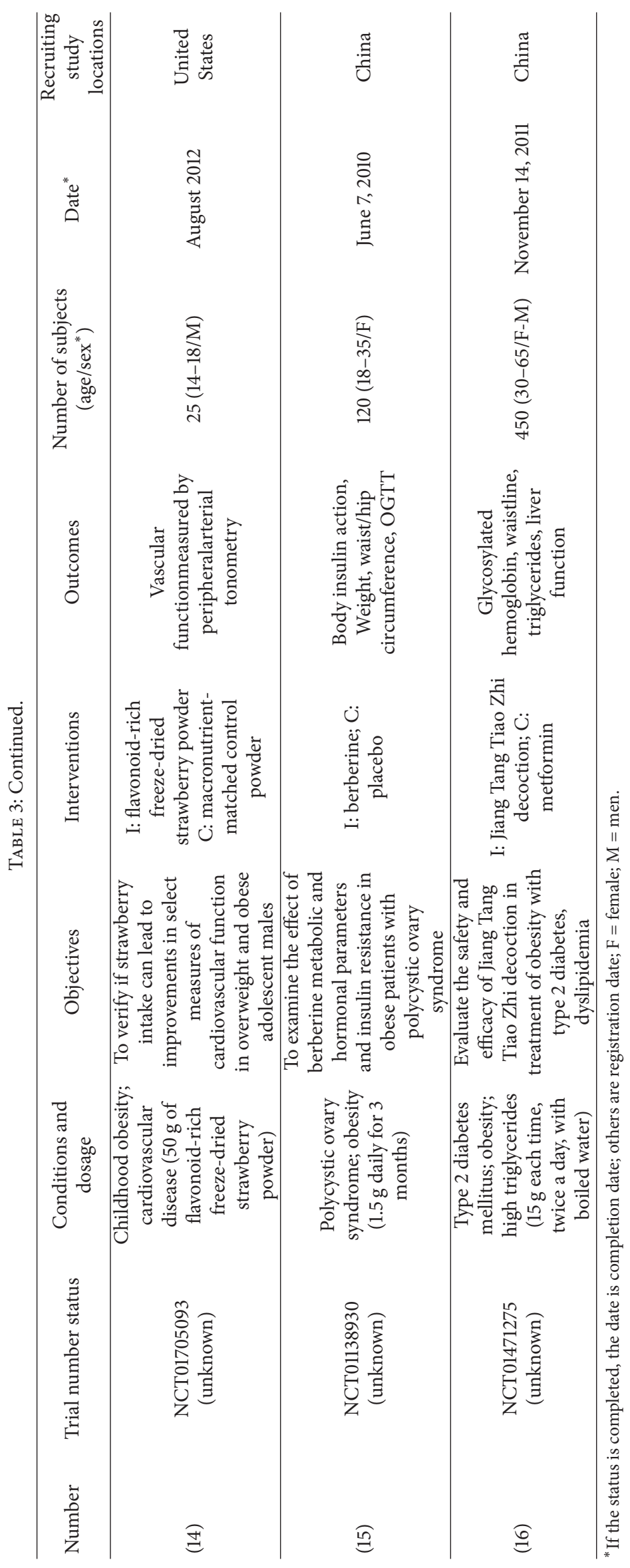




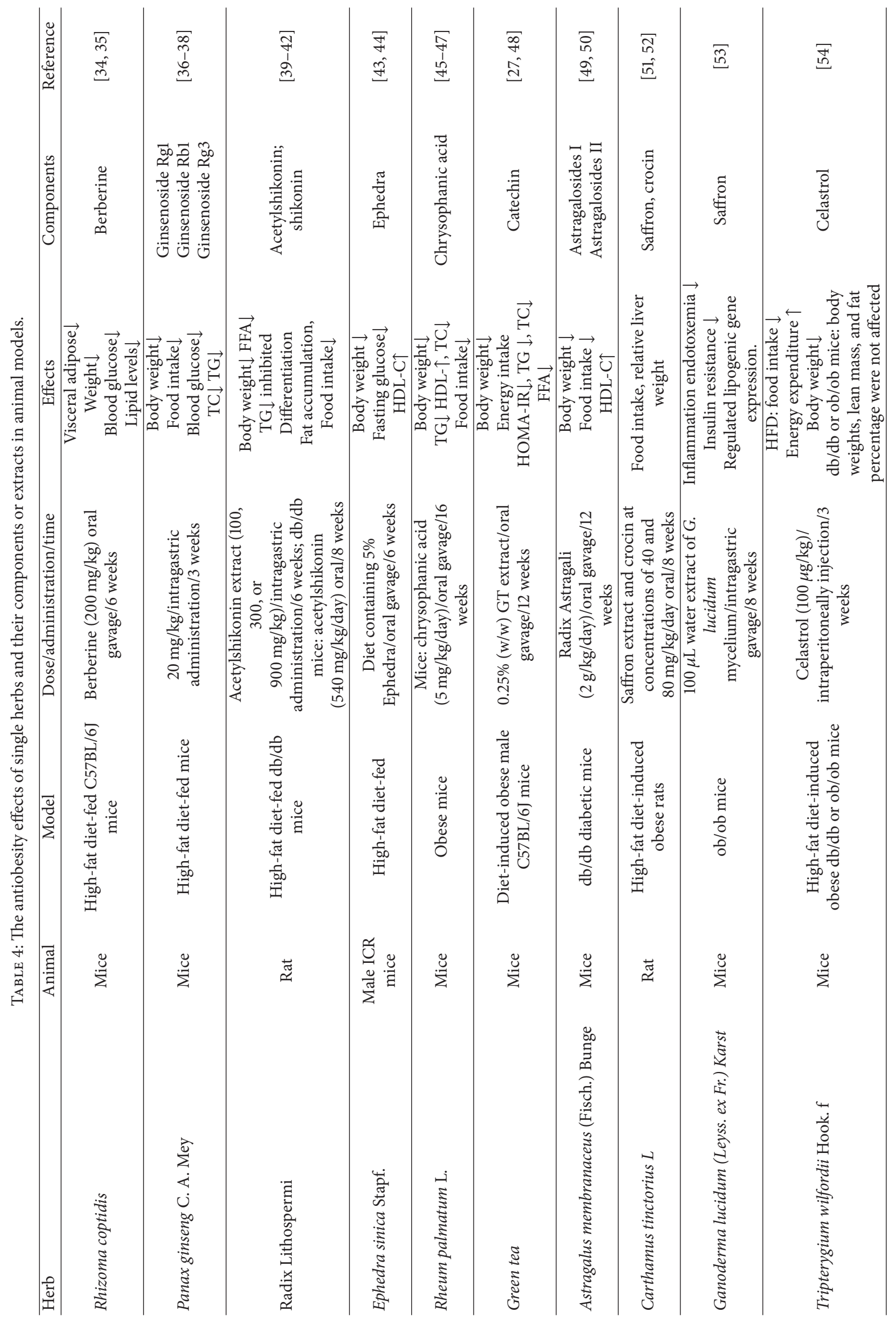


<smiles></smiles>

Berberine<smiles>Oc1cc(O)c2c(c1)O[C@H](c1ccc(O)c(O)c1)C(O)C2</smiles>

Catechin

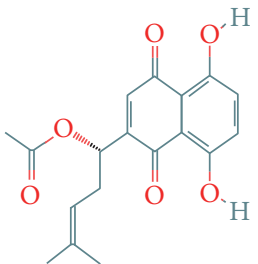

Shikonin

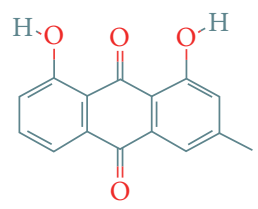

Chrysophanic acid

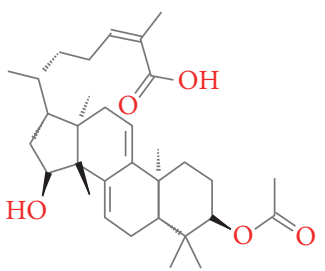

Ganoderic acid

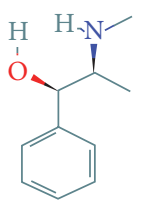

Ephedrine

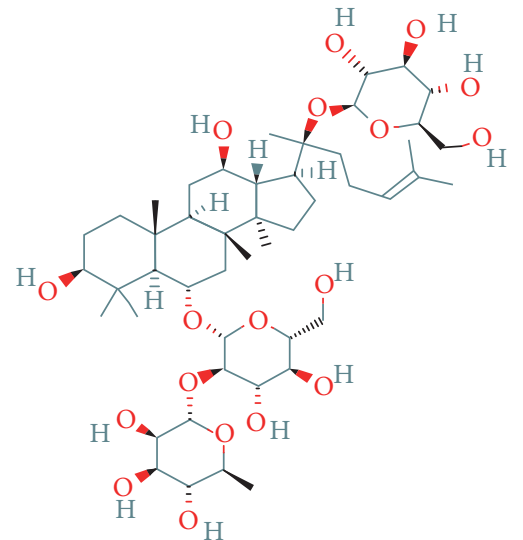

Ginsenoside

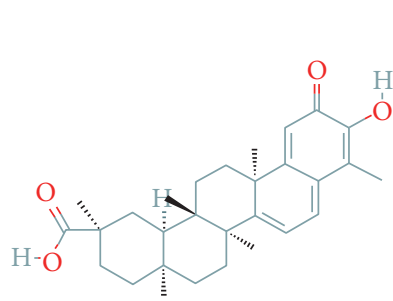

Celastrol

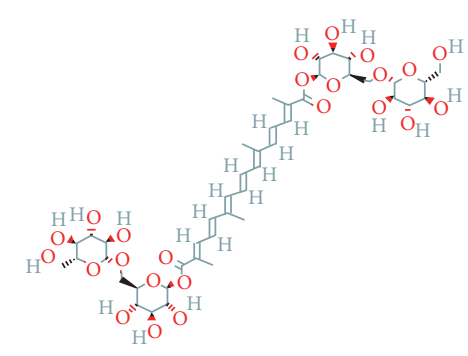

Safron

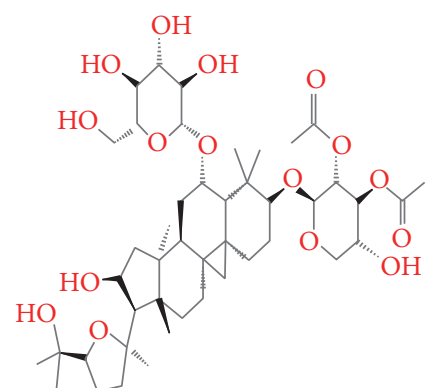

Astragaloside

FIgURE 1: Molecular structures of the compounds described in this review.

days, berberine inhibited their differentiation. Significant inhibition of intracellular lipid accumulation was observed when 3T3-L1-derived adipocytes were exposed to berberine on days $3-5$ and days $5-7$, and this effect was marked at $5 \mu \mathrm{M}$ berberine. The authors concluded that berberine suppresses adipocyte differentiation mainly by suppressing cAMP response element-binding protein (CREB) activity, which leads to a decrease in CCAAT/enhancer-binding protein beta- (C/EBP $\beta$-) triggered transcriptional cascades.

3.2.2. Panax ginseng C. A. Mey (Ren Shen). Ren Shen is derived from the dried root and rhizome of Panax ginseng C. A. Mey. (Araliaceae) [55]. Ginseng saponins and polysaccharides are the main active components of Panax ginseng C. A. Mey [60]. Ginseng saponins can be subdivided based on structure into $\mathrm{Rb} 1, \mathrm{Rb} 2, \mathrm{Rc}, \mathrm{Rd}, \mathrm{Re}$, and $\mathrm{Rl}[36,37]$. Panax ginseng C. A. Mey can reduce body weight [61], attenuate fat accumulation [62], suppress lipid accumulation and reactive oxygen species (ROS) production [63], and improve insulin resistance [64]. Li et al. [65] found that administration of ginseng $(0.5 \mathrm{~g} / \mathrm{kg}$ diet $)$ to HFD-induced obese mice for 15 weeks significantly decreased body fat mass gain, improved glucose tolerance and insulin sensitivity, and prevented hypertension. Koh et al. [63] investigated the treatment of 3T3-L1 cells with $\operatorname{Rg} 1(0,25,50,100$, and $200 \mu \mathrm{M})$. They observed that administration of $100 \mu \mathrm{M}$ Rg1 for $24 \mathrm{~h}$ greatly reduced lipid accumulation and ROS production; treatment with $100 \mu \mathrm{M} \mathrm{Rg1}$ in the early stages of 3T3-L1 differentiation (days $0-2$ ) significantly decreased adipocyte formation. Rg1 reduces lipid accumulation and ROS production via the activation of C/EBP-homologous protein 10 (CHOP10), which attenuates fat accumulation and downregulates protein levels of NADPH oxidase 4 (NOX4). Lin et al. [66] found that when daily injections of $20 \mathrm{mg} / \mathrm{kg}$ $\mathrm{Rb} 1$ were administered to diet-induced obese mice for 3 weeks, body weight, food intake, blood glucose, and lipid levels decreased significantly. The ginsenoside, Rbl, may treat obesity by modifying the serum content and mRNA expressions of neuropeptide Y (NPY), NPY Y2 receptor, and peptide YY (PYY).

3.2.3. Radix Lithospermi (Zicao). Radix Lithospermi is derived from the root of Arnebia euchroma (Royle) Johnst., Lithospermum erythrorhizon Sieb. et Zucc, or Arnebia guttata Bunge [55]. Studies have shown that Radix Lithospermi can reduce weight, inhibit lipid accumulation, induce lipolysis, and regulate lipid metabolism. The main active ingredients of Radix Lithospermi are shikonin and acetylshikonin [38, 39, $67,68]$. Su et al. [40] found that intragastric administration of 100,300 , or $900 \mathrm{mg} / \mathrm{kg}$ acetylshikonin extract for 6 weeks in 
obese rats significantly decreased weight, serum free fatty acid (FFA), and serum triglyceride (TG) levels. Acetylshikonin is effective in the treatment of obesity by suppressing the expression of adipogenic differentiation transcription factors and adipocyte-specific proteins, and by increasing the activity of cAMP-dependent protein kinase (PKA) and phosphorylation of hormone-sensitive lipase (HSL). Su et al. [41] found that oral gavage of $540 \mathrm{mg} / \mathrm{kg} /$ day of acetylshikonin for 8 weeks in $\mathrm{db} / \mathrm{db}$ mice significantly decreased body weight, food efficiency ratio, serum TG, and FFA levels. The mechanism of acetylshikonin activity in the treatment of obesity and nonalcoholic fatty liver disease involves the regulation of lipid metabolism and anti-inflammatory effects. Bettaieb et al. [42] found that administration of shikonin $(2 \mathrm{mg} / \mathrm{kg} / \mathrm{day})$ to HFD mice for 5 days at an injected volume of $1 \%$ of their body weight could improve glucose tolerance and decrease body weight, adiposity, and hepatic dyslipidemia over 18 weeks. Shikonin acts by enhancing hepatic insulin signaling, increasing tyrosine phosphorylation of the insulin receptor, and enhancing downstream signaling.

3.2.4. Ephedra sinica Stapf. (Ma Huang). The dried rhizome of Ephedra sinica Stapf. is used as the main ingredient of the herbal medicine, Ma Huang [69]. It has been used in recent years to treat obesity [43]. Other species that are used include Ephedra intermedia Schrenk et C. A. Mey. and Ephedra equisetina Bge [55]. Ephedra sinica Stapf. can modulate gut microbiota, reduce weight, and improve glucose intolerance. Song et al. [70] found that oral gavage of 5\% Ephedra and $0.5 \%$ acarbose for 6 weeks in HFD-fed mice could reduce weight gain and epididymal fat accumulation, decrease fasting blood glucose, and improve lipid profiles and glucose intolerance. The main mechanism of Ephedra sinica's ability to reduce obesity and hyperglycemia involves increasing peroxisome proliferator-activated receptor alpha (PPAR- $\alpha$ ) and adiponectin activity and reducing tumor necrosis factoralpha (TNF- $\alpha$ ) activity. The study published by Wang et al. [44] showed that administration of Ephedra sinica to HFD-induced obese rats by oral gavage over three weeks led to significant loss of body weight, epididymal fat, and perirenal fat, but no remarkable changes were observed in abdominal fat, liver weights, cecum weights, or food efficiency ratios.

3.2.5. Rheum palmatum L. (Da-Huang). Da-Huang is derived from the dried root and rhizome of Rheum palmatum L., Rheum tanguticum Maxim. ex Balf, or Rheum officinale Baill [55]. Emodin and chrysophanic acid are the active compounds of Rheum palmatum L. [71]. Lim et al. [45] found that, following administration of chrysophanic acid $(5 \mathrm{mg} / \mathrm{kg} /$ day) for 16 weeks to HFD mice, body weight, food intake, total cholesterol, low density lipoprotein (LDL) cholesterol, TG, and blood glucose decreased. In in vitro experiments, cells were cultured in medium containing chrysophanic acid for $48 \mathrm{~h}$, and the results suggested that chrysophanic acid could suppresses lipid accumulation and downregulate adipogenic factors. Chrysophanic acid can ameliorate obesity by activating $5^{\prime}$-AMP-activated protein kinase alpha (the catalytic subunit of AMPK) to control the adipogenic and thermogenic pathway. Li et al. [46] found that administration of emodin $(80 \mathrm{mg} / \mathrm{kg} /$ day $)$ for 6 weeks to HFD-induced obese mice reduced body weights and fasting blood glucose levels, while improving insulin intolerance and serum and hepatic lipid levels. Emodin likely exerts its antiobesity effect by regulating the sterol regulatory elementbinding protein (SREBP) pathway.

3.2.6. Green Tea (Lvcha). Green tea, one of the most popular teas in China, contains tea polyphenols, catechins, caffeine, and amino acids; it is frequently used to ensure weight loss [47]. Green tea induces weight loss in a variety of ways, such as activating the nuclear factor erythroid-2-relatedfactor-2 (Nrf2) pathway [72], upregulation of neprilysin [73], prevention of gut dysbiosis [74], regulating metabolic balance in the body, inhibiting fat accumulation and cholesterol synthesis, and reducing abdominal fat. Choi et al. [48] found that administration of an HFD plus $0.25 \%(\mathrm{w} / \mathrm{w})$ green tea extract for 12 weeks in diet-induced obesity (DIO) mice ameliorated obesity, hepatic steatosis, dyslipidemia, and insulin resistance. Green tea extract contributed to the regulation of systemic metabolic homeostasis via transcriptional responses to lipid, glucose, and amino acid metabolism. Zhu et al. [75] treated 3T3-L1 cells with catechins and caffeine in various concentrations and combinations for 8 or 12 days. Combination therapy with catechins and caffeine markedly reduced intracellular fat accumulation by regulating the gene and protein expression levels of lipid metabolismrelated enzymes. Yamashita et al. [76] found that, following supplementation with green tea extract powder and eriodictyol for 8 weeks, body weight, food intake, cholesterol levels, and LDL levels were decreased, accompanied by the suppression of two kinds of cholesterol synthesis enzymes, 3-hydroxy-3-methylglutaryl-coenzyme A reductase (HMGCR), and 3-hydroxy-3-methylglutaryl-coenzyme A synthase (HMGCS).

3.2.7. Astragalus membranaceus (Fisch.) Bunge (Huang Qi or Radix Astragali). Huang qi is derived from the dried root of Astragalus membranaceus (Fisch.) Bunge var. mongholicus or Astragalus membranaceus (Fisch.) Bunge [55]. The main active components of Astragalus membranaceus (Fisch.) Bunge are astragaloside, campanulin, ononin, kaempferol, and astragalus polysaccharides [77]. Xu et al. [49] found that when cells were incubated with isoastragaloside I (HQ1) and astragalosides II (HQ2), extracts of Radix Astragali, for $72 \mathrm{~h}$, insulin resistance, and glucose intolerance were improved. Oral gavage with HQ1 and HQ2 (50 mg of each compound/kg body weight, twice a day) for 6 weeks in $\mathrm{db} / \mathrm{db}$ mice increased serum levels of total adiponectin, possibly via activation of AMPK. The study published by Hoo et al. [78] suggested that daily oral gavage with Radix Astragali $(2 \mathrm{~g} / \mathrm{kg} / \mathrm{day})$ in $\mathrm{db} / \mathrm{db}$ diabetic mice for 12 weeks reduces body weight and food intake and alleviates glucose intolerance/insulin resistance. The main mechanism may be the suppression of inflammatory pathways. 
3.2.8. Carthamus tinctorius L. (Hong Hua). Carthamus tinctorius L. is derived from the dried flower of Crocus sativus L. The main active component of Carthamus tinctorius L. is saffron [50]. The study published by Zhu et al. [52] showed that HFD-induced obese male ICR mice, intraperitoneally injected with safflower yellow $(120 \mathrm{mg} / \mathrm{kg})$ daily for eight weeks, had significant reductions in body fat mass, fasting blood glucose, and improvements in insulin sensitivity. A possible mechanism is the promotion of the browning of subcutaneous white adipose tissue (WAT) and activating the insulin receptor substrate $1 /$ Akt/glycogen synthase kinase $3 \beta$ pathway in visceral WAT. Mashmoul et al. [79] used saffron (dried stigma of Crocus sativus L. flowers) to treat obesityrelated fatty liver. They were administered saffron extract and crocin at concentrations of 40 and $80 \mathrm{mg} / \mathrm{kg} /$ day for 8 weeks in HFD-induced obese rats. Levels of liver enzymes, relative liver weights, and food intake were decreased. Saffron had a curative effect in the treatment of obesity-related fatty liver disease, but more definitive evidence of the protective effects of saffron and crocin needs to be found.

3.2.9. Ganoderma lucidum (Leyss. ex Fr.) Karst. (Lingzhi). Lingzhi is derived from the dried fruiting body of Ganoderma lucidum (Leyss. ex Fr.) [55]. Chang et al. [80] found that daily treatments for 2 months with $100 \mu \mathrm{L}$ of the water extract of Ganoderma lucidum mycelium at 2, 4, or $8 \%$ $(\mathrm{w} / \mathrm{v})$ by intragastric gavage in obese mice decreased weight gain and fat accumulation and decreased proinflammatory cytokine expression in the liver and adipose tissues in a dose-dependent manner. The $8 \%$ water extract of Ganoderma lucidum mycelium was the most effective treatment for modulating gut microbiota. The results indicate that Ganoderma lucidum reduces obesity in mice by modulating the composition of the gut microbiota, reducing endotoxemia, and preventing insulin resistance. Thyagarajan-Sahu et al. [81] found that treatment of 3T3-L1 preadipocytes with ReishiMax (RM, containing Ganoderma lucidum) $(0-300 \mu \mathrm{g} / \mathrm{mL})$ for 9 days decreased lipid accumulation, triglyceride uptake, and glycerol accumulation in a concentration-dependent manner. RM can control adipocyte differentiation and glucose uptake, possibly via suppressed expression of the adipogenic transcription factor, PPAR- $\gamma$, and enzymes and proteins responsible for lipid synthesis.

3.2.10. Tripterygium wilfordii Hook. $f$ (Lei Gong Teng or Thunder God Vine). Lei Gong Teng is derived from the dried roots, leaves, and flowers of Tripterygium wilfordii Hook. $\mathrm{f}$ [55]. Celastrol is the main active ingredient of Tripterygium wilfordii Hook. f [82]. Liu et al. [53] administered Celastrol $(100 \mu \mathrm{g} / \mathrm{kg})$ intraperitoneally for three weeks to HFDinduced obese mice and found that Celastrol suppressed food intake, improved energy expenditure, and leads up to $45 \%$ weight loss in hyperleptinemic diet-induced obese mice by increasing leptin sensitivity. Following treatment with vehicle or Celastrol $(100 \mu \mathrm{g} / \mathrm{kg}$ ) (daily, intraperitoneal) in $\mathrm{db} / \mathrm{db}$ or ob/ob mice, food intake slightly decreased during the first week, and body weight, lean mass, and fat percentage were not affected by Celastrol treatment. Celastrol is a leptin sensitizer, and its main mechanism of weight reduction is relief of endoplasmic reticulum (ER) stress and increased leptin sensitivity. In another study [83], Hu et al. identified Nur77 as a critical intracellular target of Celastrol, which induces apoptosis by targeting mitochondria. $\mathrm{Hu}$ et al. used their findings to develop a safe and effective drug to reduce weight. Thunder god vine should be used cautiously because of its complex composition [54] and potential adverse reactions [84].

\section{Conclusions and Perspectives}

The effect and the relevant mechanisms behind how herbal medicine work as an antiobesity treatment are still controversial. During the past decade, much recent progress has been made in the study of weight loss therapy with herbal medicine. Clinical investigations of herbal medicine have been shown to be effective in the treatment of obesity, and animal experiments have begun to reveal the potential mechanisms of the various herbal medicine. However, there are some limitations as follows: (1) Obesity is associated with oxidative stress, but there have been fewer reports in this area. Flos carthami has been shown to be effective against oxidative stress and further study of oxidative stress and weight loss using safflower is warranted. (2) Some herbal treatments also show some toxicity and should be used with caution. For example, the drug composition of thunder god vine is complex, and when it is used to treat obesity, liver and kidney function should be closely monitored. There are many herbal medicines that have adverse effects if used on long-term or at the incorrect dosages, so the long-term application of herbal medicine for obesity should focus on the safety evaluation; for example, in one case [18], a skin rash was reported in the XJXGF formula group, but the rash was transient and disappeared without treatment. (3) Clinical reports indicate that herbal medicines for obesity produce few adverse reactions, and their level of safety is acceptable. However, some cases of adverse reactions have been reported, such as a case of sudden death due to the use of green tea. Therefore, the use of traditional Chinese medicines should be regulated. (4) The drug composition of herbal medicine is complex, making it difficult to determine the mechanism(s) of action, unlike in western medicine. There was also a case report [85] of a 19-year-old obese man $(120 \mathrm{~kg})$ who drank large amounts of green tea (15 cups per day) with a strict diet regimen, over 2 months; he lost $30 \mathrm{~kg}$ of body weight. However, after his usual exercise, he died of left ventricular fibrillation. His most prevalent symptoms were gastrointestinal problems, such as dyspepsia, epigastric pain, and nausea, as well as headache. Only a small number of the studies included herein have reported that the use of herbal medicine preparations caused adverse reactions. The safety of long-term use of herbal medicine needs to be further explored.

Use of herbal medicine to treat obesity is currently garnering much attention. Only a small number of the active ingredients available in herbs have been identified, and if 


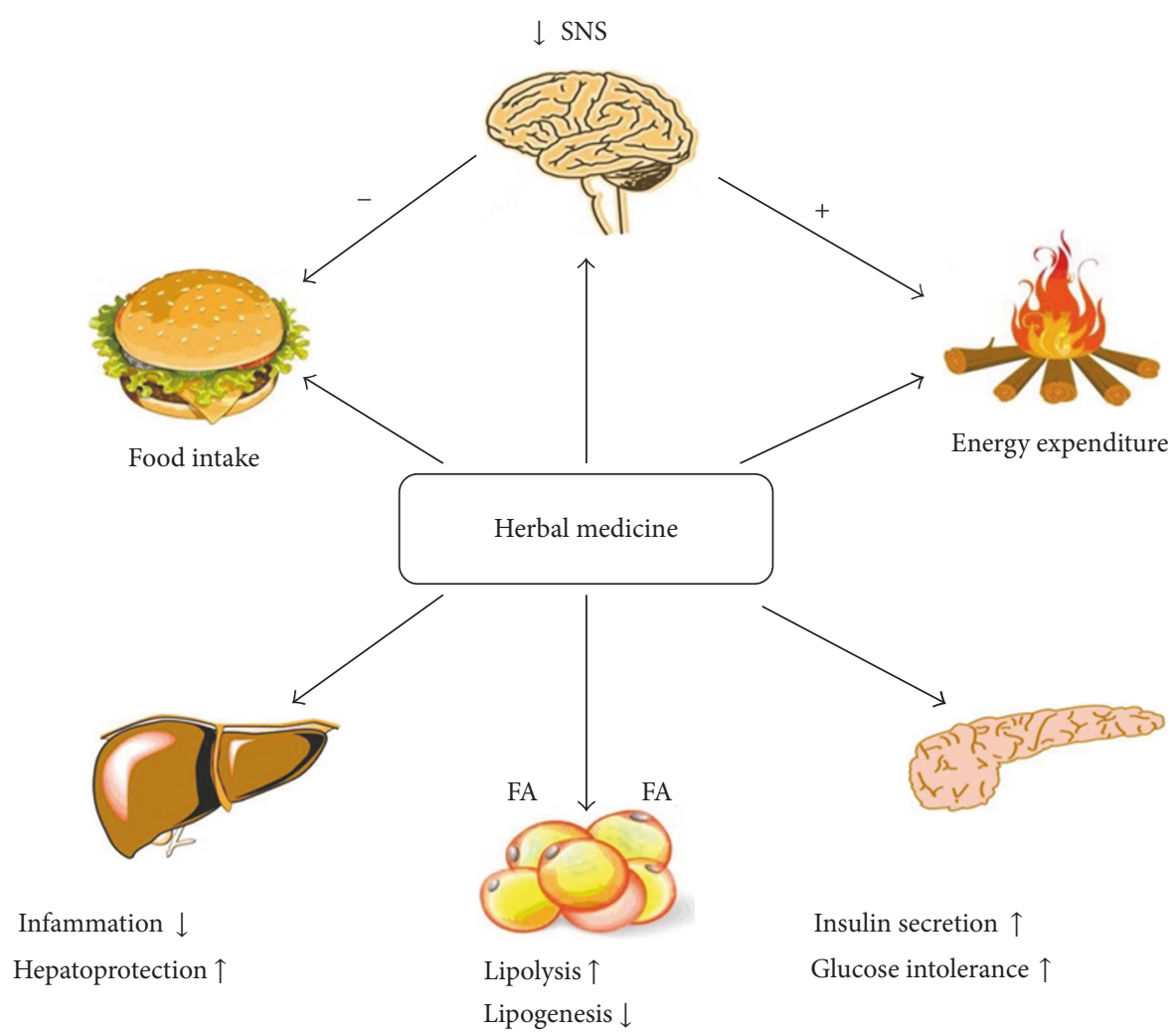

FIGURE 2: Potential mechanisms of herbal medicine for obesity. Herbal medicine such as Celastrol, its main mechanism of weight reduction is inhibiting endoplasmic reticulum (ER) stress and increased leptin sensitivity. Ganoderma lucidum mycelium decreased proinflammatory cytokine expression in the liver and adipose tissues in a dose-dependent manner; Acetylshikonin covers the treatment of obesity which involves the regulation of lipid metabolism and anti-inflammatory effects and decreased serum free fatty acid. Radix Astragali reduces body weight and food intake, and alleviates glucose intolerance/insulin resistance. SNS: sympathetic nervous system; FA: fatty acid.

the composition of the herbs is more and more identified in the future, the target and definite mechanism of action can be determined. As mentioned above, herbal medicine has some beneficial effects on the treatment of patients with obesity and has fewer adverse effects than chemical agents; potential mechanisms of herbal medicine for obesity were presented in Figure 2. Extensive preclinical and clinical researches [86] have highlighted the pharmaceutical uses of herbal medicine as antidiabetic, antihyperlipidemic, antiobesity, anti-inflammatory, and antioxidant. In clinical practice, herbal medicines are usually used in a compound form. With the development of modern pharmacological science, it is easier to identify the active agents in herbal medicine compounds, facilitating scientific study of their effectiveness. In addition, more and more clinical trials and a standardized procedure of herbal medicine producing are needed to confirm the safety and antiobesity effect of herbal medicine and finally prevent/reduce obesity by herbal medicine consumption in human.

\section{Abbreviation}

2hPG: 2 hours of postprandial blood glucose

BMI: Body mass index

BP: Blood pressure
BW: $\quad$ Body weight

CVD: Cardiovascular disease

DBP: Diastolic blood pressure

FBG: $\quad$ Fasting blood glucose

FFA: Free fatty acid

FINS: Fasting insulin

FPG: $\quad$ Fasting plasma glucose

HDL: High density lipoprotein

HFD: High-fat diet

HOMA: Homeostasis model assessment

IAF: Intraabdominal fat

IR: Insulin resistance

HbAlc: Glycated hemoglobin

OGTT: Oral glucose tolerance test

RCT: Randomized controlled trial

SBP: $\quad$ Systolic blood pressure

T2DM: Type 2 diabetes mellitus

TC: Total cholesterol

TG: Triglyceride

WC: Waist circumference.

\section{Conflicts of Interest}

The authors declare that there are no conflicts of interest. 


\section{Authors' Contributions}

Rui Gao and Yue Liu contributed to the topic conception, manuscript revision, and the decision to submit for publication and are the co-corresponding authors. Yanfei Liu and Mingyue Sun put on the references collection, references analysis, and writing of the manuscript together, contributed equally to this work, and are the co-first authors. Hezhi Yao contributed to references analysis and helped in revising manuscript.

\section{Acknowledgments}

The authors gratefully acknowledge the financial support from Special Science and Technology Research Program of Traditional Chinese Medicine of State Administration of Traditional Chinese Medicine (2016ZX10) of Professor Rui Gao, National Natural Science Foundation of China (Grant no. 81403266), and Beijing NOVA Program (no. Z171100001117027) of Dr. Yue Liu.

\section{References}

[1] Y. C. Wang, K. McPherson, T. Marsh, S. L. Gortmaker, and M. Brown, "Health and economic burden of the projected obesity trends in the USA and the UK," The Lancet, vol. 378, no. 9793, pp. 815-825, 2011.

[2] https://www.aace.com/sites/all/files/Obesity_Guidelines_Algorithm_slides_FINAL_2016.pdf.

[3] The GBD 2015 Obesity Collaborators, "Health Effects of Overweight and Obesity in 195 Countries over 25 Years," New England Journal of Medicine, vol. 377, no. 1, pp. 13-27, 2017.

[4] A. Obata, S. Okauchi, T. Kimura et al., "Advanced breast cancer in a relatively young man with severe obesity and type 2 diabetes mellitus," Journal of Diabetes Investigation, vol. 8, no. 3, pp. 395396, 2017.

[5] M. Ng, T. Fleming, M. Robinson, and et al, "Global, regional, and national prevalence of overweight and obesity in children and adults during 1980-2013: A systematic analysis for the Global Burden of Disease Study 2013," The Lancet, vol. 384, no. 9945, pp. 766-781, 2014.

[6] L. Landsberg, L. J. Aronne, L. J. Beilin et al., "Obesityrelated hypertension: Pathogenesis, cardiovascular risk, and treatment-a position paper of the obesity society and the American society of hypertension," Obesity, vol. 21, no. 1, pp. 8-24, 2013.

[7] C. Arroyo-Johnson and K. D. Mincey, "Obesity Epidemiology Worldwide," Gastroenterology Clinics of North America, vol. 45, no. 4, pp. 571-579, 2016.

[8] P. L. Lefèbvre and A. J. Scheen, "Obesity: Causes and new treatments," Experimental and Clinical Endocrinology and Diabetes, vol. 109, no. 2, pp. S215-S224, 2001.

[9] C. M. Apovian, L. J. Aronne, D. H. Bessesen et al., "Pharmacological management of obesity: an endocrine society clinical practice guideline," Journal of Clinical Endocrinology and Metabolism, vol. 100, no. 2, pp. 342-362, 2015.

[10] M. O. Dietrich and T. L. Horvath, "Limitations in anti-obesity drug development: the critical role of hunger-promoting neurons," Nature Reviews Drug Discovery, vol. 11, no. 9, pp. 675-691, 2012.
[11] E. Mead, G. Atkinson, B. Richter et al., "Drug interventions for the treatment of obesity in children and adolescents," Cochrane Database of Systematic Reviews, vol. 29, no. 11, Article ID CD012436, 2016.

[12] C. Van Der Schoor, H. M. Oberholzer, M. J. Bester, and M.-J. Van Rooy, "The effect of sibutramine, a serotoninnorepinephrine reuptake inhibitor, on platelets and fibrin networks of male Sprague-Dawley rats: A descriptive study," Ultrastructural Pathology, vol. 38, no. 6, pp. 399-405, 2014.

[13] J. J. Kim, M. E. Tarnoff, and S. A. Shikora, "Surgical Treatment for Extreme Obesity: Evolution of a Rapidly Growing Field," Nutrition in Clinical Practice, vol. 18, no. 2, pp. 109-123, 2003.

[14] S. Ikramuddin, J. Korner, W.-J. Lee et al., "Durability of addition of Roux-en-Y Gastric Bypass to lifestyle intervention and medical management in achieving primary treatment goals for uncontrolled type 2 diabetes in mild to moderate obesity: A randomized control trial," Diabetes Care, vol. 39, no. 9, pp. 15101518, 2016.

[15] J. Y. Park and Y. J. Kim, "Laparoscopic Roux-en-Y gastric bypass in obese Korean patients: efficacy and potential adverse events," Surgery Today, vol. 46, no. 3, pp. 348-355, 2016.

[16] J. E. Lambert, J. A. Parnell, J. M. Tunnicliffe, J. Han, T. Sturzenegger, and R. A. Reimer, "Consuming yellow pea fiber reduces voluntary energy intake and body fat in overweight/obese adults in a 12-week randomized controlled trial," Clinical Nutrition, 2015.

[17] K. Azushima, K. Tamura, S. Haku et al., "Effects of the oriental herbal medicine Bofu-tsusho-san in obesity hypertension: A multicenter, randomized, parallel-group controlled trial (ATHD-14-01021.R2)," Atherosclerosis, vol. 240, no. 1, pp. 297-304, 2015.

[18] Q. Zhou, B. Chang, X.-Y. Chen et al., "Chinese herbal medicine for obesity: A randomized, double-blinded, multicenter, prospective trial," American Journal of Chinese Medicine, vol. 42, no. 6, pp. 1345-1356, 2014.

[19] G. B. Lenon, K. X. Li, Y.-H. Chang et al., "Efficacy and safety of a Chinese herbal medicine formula (RCM-104) in the management of simple obesity: A randomized, placebocontrolled clinical trial," Evidence-based Complementary and Alternative Medicine, vol. 2012, Article ID 435702, 2012.

[20] B. Ke, L. Shi, J.-J. Zhang, D.-S. Chen, J. Meng, and J. Qin, "Protective effects of Modified Linggui Zhugan Decoction combined with short-term very low calorie diets on cardiovascular risk factors in obese patients with impaired glucose tolerance," Journal of Traditional Chinese Medicine, vol. 32, no. 2, pp. 193198, 2012.

[21] S.-L. Chu, H. Fu, J.-X. Yang et al., "A randomized double-blind placebo-controlled study of Pu'er tea extract on the regulation of metabolic syndrome," Chinese Journal of Integrative Medicine, vol. 17, no. 7, pp. 492-498, 2011.

[22] Z. Li, R. Song, C. Nguyen et al., "Pistachio nuts reduce triglycerides and body weight by comparison to refined carbohydrate snack in obese subjects on a 12-week weight loss program," Journal of the American College of Nutrition, vol. 29, no. 3, pp. 198-203, 2010.

[23] M. Abidov, Z. Ramazanov, R. Seifulla, and S. Grachev, "The effects of Xanthigen in the weight management of obese premenopausal women with non-alcoholic fatty liver disease and normal liver fat," Diabetes, Obesity and Metabolism, vol. 12, no. 1, pp. 72-81, 2010.

[24] B. Gout, C. Bourges, and S. Paineau-Dubreuil, "Satiereal, a Crocus sativus L extract, reduces snacking and increases satiety in a randomized placebo-controlled study of mildly overweight, 
healthy women," Nutrition Research, vol. 30, no. 5, pp. 305-313, 2010.

[25] E. A. Datau, Wardhana, E. E. Surachmanto, K. Pandelaki, J. A. Langi, and Fias, "Efficacy of Nigella sativa on serum free testosterone and metabolic disturbances in central obese male," Acta Medica Indonesiana, vol. 42, no. 3, pp. 130-134, 2010.

[26] F. Di Pierro, A. B. Menghi, A. Barreca, M. Lucarelli, and A. Calandrelli, "GreenSelect phytosome as an adjunct to a lowcalorie diet for treatment of obesity: A clinical trial," Alternative Medicine Review, vol. 14, no. 2, pp. 154-160, 2009.

[27] H. Wang, Y. Wen, Y. Du et al., "Effects of catechin enriched green tea on body composition," Obesity, vol. 18, no. 4, pp. 773779, 2010.

[28] R.-R. He, L. Chen, B.-H. Lin, Y. Matsui, X.-S. Yao, and H. Kurihara, "Beneficial effects of oolong tea consumption on dietinduced overweight and obese subjects," Chinese Journal of Integrative Medicine, vol. 15, no. 1, pp. 34-41, 2009.

[29] J. L. Ngondi, B. C. Etoundi, C. B. Nyangono, C. M. F. Mbofung, and J. E. Oben, "IGOB131, a novel seed extract of the West African plant Irvingia gabonensis, significantly reduces body weight and improves metabolic parameters in overweight humans in a randomized double-blind placebo controlled investigation," Lipids in Health and Disease, vol. 8, article no. 7, 2009.

[30] J. E. Oben, J. L. Ngondi, C. N. Momo, G. A. Agbor, and C. S. M. Sobgui, "The use of a Cissus quadrangularis/Irvingia gabonensis combination in the management of weight loss: A double-blind placebo-controlled study," Lipids in Health and Disease, vol. 7, article no. 12, 2008.

[31] C. Roongpisuthipong, R. Kantawan, and W. Roongpisuthipong, "Reduction of adipose tissue and body weight: effect of water soluble calcium hydroxycitrate in Garcinia atroviridis on the short term treatment of obese women in Thailand," Asia Pacific Journal of Clinical Nutrition, vol. 16, no. 1, pp. 25-29, 2007.

[32] R. Kuriyan, T. Raj, S. K. Srinivas, M. Vaz, R. Rajendran, and A. V. Kurpad, "Effect of Caralluma Fimbriata extract on appetite, food intake and anthropometry in adult Indian men and women," Appetite, vol. 48, no. 3, pp. 338-344, 2007.

[33] J. E. Oben, D. M. Enyegue, G. I. Fomekong, Y. B. Soukontoua, and G. A. Agbor, "The effect of Cissus quadrangularis (CQR$300)$ and a Cissus formulation (CORE) on obesity and obesityinduced oxidative stress," Lipids in Health and Disease, vol. 6, article no. 4, 2007.

[34] W.-J. Ni, H.-H. Ding, and L.-Q. Tang, "Berberine as a promising anti-diabetic nephropathy drug: An analysis of its effects and mechanisms," European Journal of Pharmacology, vol. 760, pp. 103-112, 2015.

[35] W. Xie, D. Gu, J. Li, K. Cui, and Y. Zhang, "Effects and action mechanisms of berberine and rhizoma coptidis on gut microbes and obesity in high-fat diet-fed C57BL/6J mice," PLoS ONE, vol. 6, no. 9, Article ID e24520, 2011.

[36] L. P. Christensen, "Chapter 1 ginsenosides: chemistry, biosynthesis, analysis, and potential health effects," Advances in Food and Nutrition Research, vol. 55, pp. 1-99, 2008.

[37] S. A. Palaniyandi, J. W. Suh, and S. H. Yang, "Preparation of ginseng extract with enhanced levels of ginsenosides Rg1 and Rb1 using high hydrostatic pressure and polysaccharide hydrolases," Pharmacognosy Magazine, vol. 13, 1, no. 49, pp. 142147, 2017.

[38] X. Zhang, J. Cui, Q. Meng, S. Li, W. Zhou, and S. Xiao, "Advance in anti-tumor mechanisms of shikonin, alkannin and their derivatives," Mini-Reviews in Medicinal Chemistry, vol. 17, no. $18,2017$.

[39] X. Chen, L. Yang, J. J. Oppenheim, and O. M. Z. Howard, “Cellular pharmacology studies of shikonin derivatives," Phytotherapy Research, vol. 16, no. 3, pp. 199-209, 2002.

[40] M. Su, W. Huang, and B. Zhu, "Acetylshikonin from Zicao prevents obesity in rats on a high-fat diet by inhibiting lipid accumulation and inducing lipolysis," PLoS ONE, vol. 11, no. 1, Article ID e0146884, 2016.

[41] M.-L. Su, Y. He, Q.-S. Li, and B.-H. Zhu, "Efficacy of acetylshikonin in preventing obesity and hepatic steatosis in $\mathrm{db} / \mathrm{db}$ mice," Molecules, vol. 21, no. 8, article 976, 2016.

[42] A. Bettaieb, E. Hosein, S. Chahed et al., "Decreased adiposity and enhanced glucose tolerance in shikonin treated mice," Obesity, vol. 24, no. 5, pp. 2269-2277, 2016.

[43] E. A. Abourashed, A. T. El-Alfy, I. A. Khan, and L. Walker, "Ephedra in perspective-a current review," Phytotherapy Research, vol. 17, no. 7, pp. 703-712, 2003.

[44] J.-H. Wang, B.-S. Kim, K. Han, and H. Kim, "Ephedra-treated donor-derived gut microbiota transplantation ameliorates high fat diet-induced obesity in rats," International Journal of Environmental Research and Public Health, vol. 14, aricle 555, no. 6, 2017.

[45] H. Lim, J. Park, H.-L. Kim et al., "Chrysophanic acid suppresses adipogenesis and induces thermogenesis by activating AMPactivated protein kinase alpha in vivo and in vitro," Frontiers in Pharmacology, vol. 4, article 476, no. 7, 2016.

[46] J. Li, L. Ding, B. Song et al., "Emodin improves lipid and glucose metabolism in high fat diet-induced obese mice through regulating SREBP pathway," European Journal of Pharmacology, vol. 770, pp. 99-109, 2016.

[47] D. Türközü and N. A. Tek, "A minireview of effects of green tea on energy expenditure," Critical Reviews in Food Science and Nutrition, vol. 57, no. 2, pp. 254-258, 2017.

[48] J.-Y. Choi, Y. J. Kim, R. Ryu, S.-J. Cho, E.-Y. Kwon, and M.S. Choi, "Effect of green tea extract on systemic metabolic homeostasis in diet-induced obese mice determined via RNAseq transcriptome profiles," Nutrients, vol. 8 , no. 10, article no. 640, 2016.

[49] A. Xu, H. Wang, R. L. C. Hoo et al., "Selective elevation of adiponectin production by the natural compounds derived from a medicinal herb alleviates insulin resistance and glucose intolerance in obese mice," Endocrinology, vol. 150, no. 2, pp. 625-633, 2009.

[50] E. Christodoulou, N. P. Kadoglou, N. Kostomitsopoulos, and G. Valsami, "Saffron: A natural product with potential pharmaceutical applications," Journal of Pharmacy and Pharmacology, vol. 67, no. 12, pp. 1634-1649, 2015.

[51] M. Mashmoul, A. Azlan, N. Mohtarrudin et al., "Protective effects of saffron extract and crocin supplementation on fatty liver tissue of high-fat diet-induced obese rats," BMC Complementary and Alternative Medicine, vol. 16, no. 1, article 401, 2016.

[52] H. Zhu, X. Wang, H. Pan et al., "The mechanism by which safflower yellow decreases body fat mass and improves insulin sensitivity in HFD-induced obese mice," Frontiers in Pharmacology, vol. 7, no. MAY, article 127, 2016.

[53] J. Liu, J. Lee, M. Salazar Hernandez, R. Mazitschek, and U. Ozcan, "Treatment of obesity with celastrol," Cell, vol. 161, no. 5, pp. 999-1011, 2015.

[54] S. K.-Y. Law, M. P. Simmons, N. Techen et al., "Molecular analyses of the Chinese herb Leigongteng (Tripterygium wilfordii Hook.f.)," Phytochemistry, vol. 72, no. 1, pp. 21-26, 2011. 
[55] Chinese Pharmacopoeia Commission, Pharmacopoeia of the People's Republic of China, Chinese Medical Science Press, Beijing, China, 2010.

[56] Z.-Y. Zou, Y.-R. Hu, H. Ma et al., "Coptisine attenuates obesityrelated inflammation through LPS/TLR-4-mediated signaling pathway in Syrian golden hamsters," Fitoterapia, vol. 105, pp. 139-146, 2015.

[57] W.-L. Zhang, L. Zhu, and J.-G. Jiang, "Active ingredients from natural botanicals in the treatment of obesity," Obesity Reviews, vol. 15, no. 12, pp. 957-967, 2014.

[58] J. S. Choi, J.-H. Kim, M. Y. Ali, B.-S. Min, G.-D. Kim, and H. A. Jung, "Coptis chinensis alkaloids exert anti-adipogenic activity on 3T3-L1 adipocytes by downregulating C/EBP- $\alpha$ and PPARy," Fitoterapia, vol. 98, pp. 199-208, 2014.

[59] J. Zhang, H. Tang, R. Deng et al., "Berberine suppresses adipocyte differentiation via decreasing CREB transcriptional activity," PLoS ONE, vol. 10, no. 4, Article ID e0125667, 2015.

[60] Y. Li, T. J. Zhang, S. X. Liu, R. R. Wang, and J. Luo, "Research on chemical compositions and pharmacology role of Gingeng," Chinese Traditional and Herbal Drugs, vol. 40, no. 1, pp. 164-166, 2009.

[61] M. C. Kho, Y. J. Lee, J. H. Park et al., "Fermented red ginseng potentiates improvement of metabolic dysfunction in metabolic syndrome rat models," Nutrients, vol. 8, no. 6, article 369, 2016.

[62] N. Karu, R. Reifen, and Z. Kerem, "Weight gain reduction in mice fed Panax ginseng saponin, a pancreatic lipase inhibitor," Journal of Agricultural and Food Chemistry, vol. 55, no. 8, pp. 2824-2828, 2007.

[63] E.-J. Koh, K.-J. Kim, J. Choi, H. J. Jeon, M.-J. Seo, and B.Y. Lee, "Ginsenoside Rg1 suppresses early stage of adipocyte development via activation of C/EBP homologous protein-10 in 3T3-L1 and attenuates fat accumulation in high fat diet-induced obese zebrafish," Journal of Ginseng Research, 2015.

[64] J.-M. Cheon, D.-I. Kim, and K.-S. Kim, "Insulin sensitivity improvement of fermented Korean red ginseng (Panax ginseng) mediated by insulin resistance hallmarks in old-aged ob/ob mice," Journal of Ginseng Research, vol. 39, no. 4, pp. 331-337, 2015.

[65] X. Li, J. Luo, P. V. A. Babu et al., "Dietary supplementation of chinese ginseng prevents obesity and metabolic syndrome in high-fat diet-fed mice," Journal of Medicinal Food, vol. 17, no. 12, pp. 1287-1297, 2014.

[66] N. Lin, D. Cai, D. Jin, Y. Chen, and J. Shi, "Ginseng panaxoside $\mathrm{Rb} 1$ reduces body weight in diet-induced obese mice," Cell Biochemistry and Biophysics, vol. 68, no. 1, pp. 189-194, 2014.

[67] S.-H. Park, N. M. Phuc, J. Lee et al., "Identification of acetylshikonin as the novel CYP2J2 inhibitor with anti-cancer activity in HepG2 cells," Phytomedicine, vol. 24, pp. 134-140, 2017.

[68] Y. He, Q. Li, M. Su, W. Huang, and B. Zhu, "Acetylshikonin from Zicao exerts antifertility effects at high dose in rats by suppressing the secretion of GTH," Biochemical and Biophysical Research Communications, vol. 476, no. 4, pp. 560-565, 2016.

[69] R. Gul, S. U. Jan, S. Faridullah, S. Sherani, and N. Jahan, "Preliminary Phytochemical Screening, Quantitative Analysis of Alkaloids, and Antioxidant Activity of Crude Plant Extracts from Ephedra intermedia Indigenous to Balochistan," Scientific World Journal, vol. 2017, Article ID 5873648, 2017.

[70] M.-K. Song, J.-Y. Um, H.-J. Jang, and B.-C. Lee, "Beneficial effect of dietary Ephedra sinica on obesity and glucose intolerance in high-fat diet-fed mice," Experimental and Therapeutic Medicine, vol. 3, no. 4, pp. 707-712, 2012.
[71] L. Liu, L. Fan, H. Chen, X. Chen, and Z. Hu, "Separation and determination of four active anthraquinones in Chinese herbal preparations by flow injection-capillary electrophoresis," Electrophoresis, vol. 26, no. 15, pp. 2999-3006, 2005.

[72] C. Sampath, M. R. Rashid, S. Sang, and M. Ahmedna, "Green tea epigallocatechin 3-gallate alleviates hyperglycemia and reduces advanced glycation end products via nrf2 pathway in mice with high fat diet-induced obesity," Biomedicine and Pharmacotherapy, vol. 87, pp. 73-81, 2017.

[73] M. Muenzner, N. Tappenbeck, F. Gembardt et al., "Green tea reduces body fat via upregulation of neprilysin," International Journal of Obesity, vol. 40, no. 12, pp. 1850-1855, 2016.

[74] M. Cheng, X. Zhang, Y. Miao, J. Cao, Z. Wu, and P. Weng, “The modulatory effect of (-)-epigallocatechin 3-O-(3-O-methyl) gallate (EGCG3"Me) on intestinal microbiota of high fat dietinduced obesity mice model," Food Research International, vol. 92, pp. 9-16, 2017.

[75] X. Zhu, L. Yang, F. Xu, L. Lin, and G. Zheng, "Combination therapy with catechins and caffeine inhibits fat accumulation in 3T3-L1 cells," Experimental and Therapeutic Medicine, vol. 13, no. 2, pp. 688-694, 2017.

[76] M. Yamashita, M. Kumazoe, Y. Nakamura et al., "The combination of green tea extract and eriodictyol inhibited high-fat/highsucrose diet-induced cholesterol upregulation is accompanied by suppression of cholesterol synthesis enzymes," Journal of Nutritional Science and Vitaminology, vol. 62, no. 4, pp. 249256, 2016.

[77] H. Li, F. Xu, P. Yang et al., "Systematic screening and characterization of prototype constituents and metabolites of total astragalosides using HPLC-ESI-IT-TOF-MSn after oral administration to rats," Journal of Pharmaceutical and Biomedical Analysis, vol. 142, pp. 102-112, 2017.

[78] R. L. C. Hoo, J. Y. L. Wong, C. F. Qiao, A. Xu, H. X. Xu, and K. S. L. Lam, "The effective fraction isolated from Radix Astragali alleviates glucose intolerance, insulin resistance and hypertriglyceridemia in $\mathrm{db} / \mathrm{db}$ diabetic mice through its antiinflammatory activity," Nutrition and Metabolism, vol. 7, article 67, 2010.

[79] M. Mashmoul, A. Azlan, N. Mohtarrudin et al., "Protective effects of saffron extract and crocin supplementation on fatty liver tissue of high-fat diet-induced obese rats," BMC Complementary and Alternative Medicine, vol. 16, article 401, no. 1, 2016.

[80] C. Chang, C. Lin, C. Lu et al., "Ganoderma lucidum reduces obesity in mice by modulating the composition of the gut microbiota," Nature Communications, vol. 23, article 7489, no. 6, 2015.

[81] A. Thyagarajan-Sahu, B. Lane, and D. Sliva, "ReishiMax, mushroom based dietary supplement, inhibits adipocyte differentiation, stimulates glucose uptake and activates AMPK," BMC Complementary and Alternative Medicine, vol. 11, article 74, 2011.

[82] M. Li, X. Liu, Y. He et al., "Celastrol attenuates angiotensin II mediated human umbilical vein endothelial cells damage through activation of Nrf2/ERK1/2/Nox2 signal pathway," European Journal of Pharmacology, vol. 797, pp. 124-133, 2017.

[83] M. Hu, Q. Luo, G. Alitongbieke et al., "Celastrol-induced Nur77 interaction with TRAF2 alleviates inflammation by promoting mitochondrial ubiquitination and autophagy," Molecular Cell, vol. 66, no. 1, pp. 141-153, 2017.

[84] S. Zhao, F. Otieno, A. Akpan, and R. J. Moots, "Complementary and Alternative Medicine Use in Rheumatoid Arthritis: Considerations for the Pharmacological Management of Elderly Patients," Drugs and Aging, vol. 34, no. 4, pp. 255-264, 2017. 
[85] J. Najafian, M. Abdar-Esfahani, M. Arab-Momeni, and A. Akhavan-Tabib, "Safety of herbal medicine in treatment of weight loss," ARYA Atherosclerosis, vol. 10, no. 1, pp. 55-58, 2014.

[86] J. Martel, D. M. Ojcius, C.-J. Chang et al., "Anti-obesogenic and antidiabetic effects of plants and mushrooms," Nature Reviews Endocrinology, vol. 13, no. 3, pp. 149-160, 2017. 


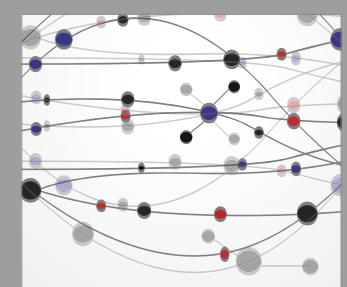

The Scientific World Journal
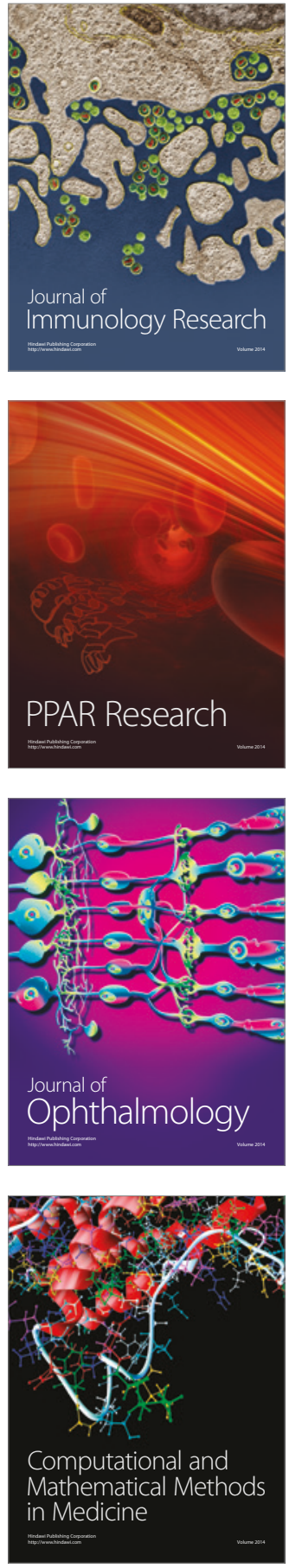

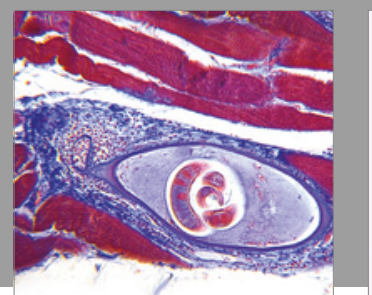

Gastroenterology Research and Practice
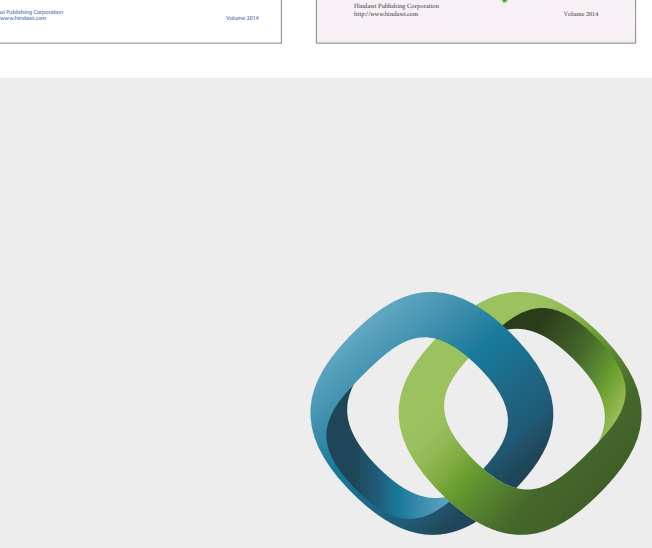

\section{Hindawi}

Submit your manuscripts at

https://www.hindawi.com
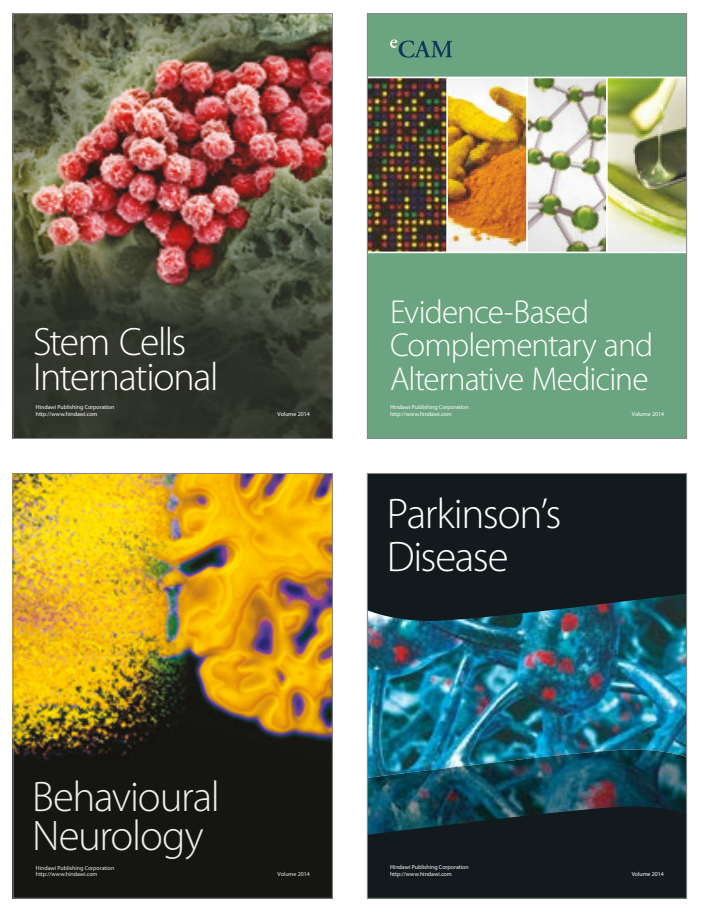
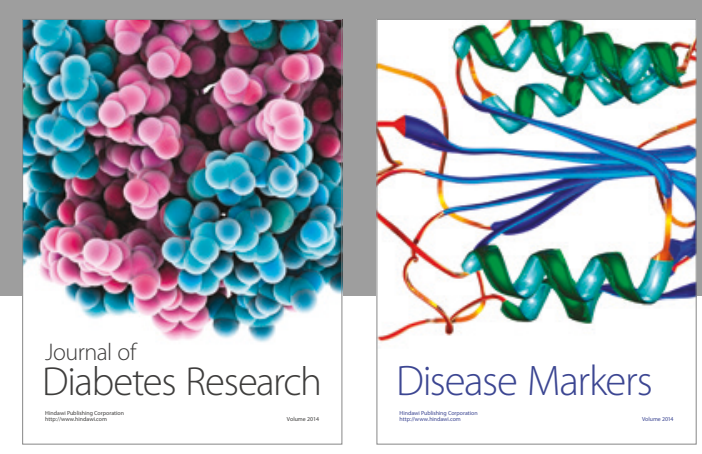

Disease Markers
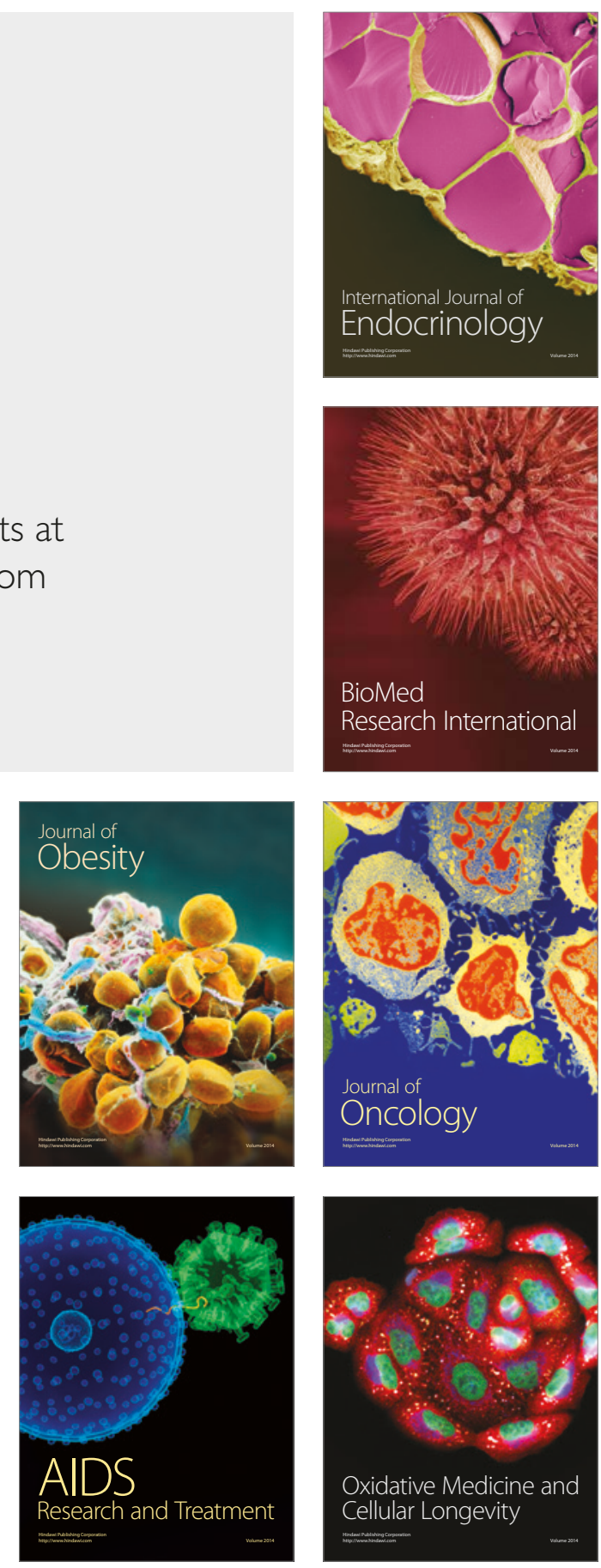